\title{
The Research on Low Carbon Logistics Routing Optimization Based on DNA-Ant Colony Algorithm
}

\author{
Liyi Zhang, ${ }^{1}$ Ying Wang, ${ }^{2}$ Teng Fei, ${ }^{1}$ and Hongwei Ren ${ }^{3}$ \\ ${ }^{1}$ Information Engineering College, Tianjin University of Commerce, Tianjin 300134, China \\ ${ }^{2}$ Economic College, Tianjin University of Commerce, Tianjin 300134, China \\ ${ }^{3}$ Waston Engineering Shool, State University of New York at Binghamton, 138 Conklin Avenue, Binghamton, NY 13902, USA
}

Correspondence should be addressed to Teng Fei; fei_8825@163.com

Received 11 April 2014; Accepted 15 May 2014; Published 22 June 2014

Academic Editor: Xiang Li

Copyright (C) 2014 Liyi Zhang et al. This is an open access article distributed under the Creative Commons Attribution License, which permits unrestricted use, distribution, and reproduction in any medium, provided the original work is properly cited.

\begin{abstract}
As the energy conservation and emission reduction and sustainable development have become the hot topics in the world, low carbon issues catch more and more attention. Logistics, which is one of the important economic activities, plays a crucial role in the low carbon development. Logistics leads to some significant issues about consuming energy and carbon emissions. Therefore, reducing energy consumption and carbon emissions has become the inevitable trend for logistics industry. Low carbon logistics is introduced in these situations. In this paper, from the microcosmic aspects, we will bring the low carbon idea in the path optimization issues and change the amount of carbon emissions into carbon emissions cost to establish the path optimization model based on the optimization objectives of the lowest cost of carbon emissions. According to different levels of air pollution, we will establish the double objectives path optimization model with the consideration of carbon emissions cost and economy cost. Use DNA-ant colony algorithm to optimize and simulate the model. The simulation indicates that DNA-ant colony algorithm could find a more reasonable solution for low carbon logistics path optimization problems.
\end{abstract}

\section{Introduction}

As the energy conservation and emission reduction and sustainable development has become the hot topics in the world, low carbon issues catch more and more attention. Logistics, which is one important economic activity, plays a crucial role in the low carbon development. Logistics leads to some significant issues about consuming energy and carbon emissions. Therefore, reducing energy consumption and carbon emissions have become the inevitable trend for logistics industry. Low carbon logistics is introduced in these situations. Low carbon logistics means that the processes of logistics, based on the goals of low energy consumption, low pollution, and low emissions, use the technology of energy efficiency, renewable energy, and reducing greenhouse gas emissions to restrain the harm to environment, which would be also helpful for the purification of the logistics environment and get the full use of logistics resources. It includes logistics operation part and the whole process of low carbon logistics management [1]. Logistics operation links include logistics system works optimization, such as reasonable planning distribution path, improving logistics efficiency, reducing resources waste, and taking full use of logistics resources. Logistics management includes using all kinds of low carbon technologies to improve logistics system, which will reduce the carbon emissions in the processes of transportation.

Low carbon logistics is one frontier domain of research, which catches more and more attention of scholars. Most low carbon logistics researches are focused on the macroscopic aspects, which are the qualitative researches of low carbon logistics, including low carbon logistics itself analysis [2-5], low carbon logistics system analysis [6-8], and low carbon logistics network analysis [9-11]. However, there are only few researches about microscopic aspects of low carbon logistics.

In this paper, from the microcosmic aspects, we bring the low carbon idea in the path optimization issues and change the amount of carbon emissions into carbon emissions cost to 
establish the path optimization model based on the optimization objectives of lowest cost of carbon emissions. According to different levels of air pollution, we establish the double objectives path optimization model with the consideration of carbon emissions cost and economy cost. We will use DNAant colony algorithm to optimize and simulate the model. The simulation indicates that DNA-ant colony algorithm could find a more reasonable solution for low carbon logistics path optimization problems.

\section{Modeling}

2.1. Distribution Optimization Model of Minimum Cost of Carbon Emissions. Low carbon logistics is a kind of low energy cost and low pollution logistics whose goal is to achieve the highest efficiency of logistics with the lowest greenhouse gas emissions [12]. Relevant data shows that thermal power emission, vehicle exhaust emissions, and construction are the main sources of carbon dioxide emissions. Bearing the social goods transportation, storage, packaging, processing, distribution, loading, unloading, and other services, logistics has become the big one for the carbon emissions. Looking for the reasonable distribution route to reduce carbon emissions is particularly important. The reduction in carbon emissions model reflects the reduction of carbon emissions cost. Therefore, this paper established low carbon logistics distribution route optimization model to achieve the minimizing carbon emissions.

2.1.1. The Calculation of Cost of Carbon Emissions. As the vehicles pickup or delivery goods in the different order crossing all customers, the car load changes. With the increase of vehicle load, the unit distance fuel consumption rises, leading to the increase of carbon emissions cost [13]. With the increase of vehicle transport distance, carbon emissions cost will also increase. Thus, the cost of carbon emissions does not only has relationship with transport distance but is also related to the vehicles' load.

The unit distance fuel consumption $\varepsilon(q)$ has a linear relationship with the total weight of the vehicles $q_{\text {sum }}$, which is

$$
\varepsilon(q)=\delta q_{\text {sum }}+b=\delta\left(q+q_{0}\right)+b,
$$

where $\varepsilon(q)$ is the unit distance fuel consumption, $\delta$ is the relationship factor between the unit distance fuel consumption and vehicles' weight, and $q_{\text {sum }}$ is the total weight of the vehicles including vehicle loading weight $q$ and vehicle's weight $q_{0}$.

When vehicles are full, the unit distance fuel consumption is $\varepsilon^{*}$, which is

$$
\varepsilon^{*}=\delta\left(Q+q_{0}\right)+b,
$$

where $\varepsilon^{*}$ is the unit distance fuel consumption when vehicles are full and $Q$ is the vehicles' maximum load.

When vehicles are empty, the unit distance fuel consumption is $\varepsilon_{0}$, which is

$$
\varepsilon_{0}=\delta q_{0}+b
$$

From formula (2) and formula (3), we can get

$$
\delta=\frac{\varepsilon^{*}-\varepsilon_{0}}{Q}
$$

Bring formula (4) into formula (1); the unit distance fuel consumption $\varepsilon(q)$ is as follows:

$$
\begin{aligned}
\varepsilon(q) & =\delta q_{\text {sum }}+b=\delta\left(q+q_{0}\right)+b \\
& =\delta q+\left(\delta q_{0}+b\right)=\frac{\varepsilon^{*}-\varepsilon_{0}}{Q} q+\varepsilon_{0} .
\end{aligned}
$$

Thus, the carbon emissions cost $\mathrm{CO}_{2}\left(q_{i j}\right)$ of the goods with the weight $q_{i}$ from customer $i$ to customer $j$ is as follows:

$$
\mathrm{CO}_{2}\left(q_{i j}\right)=c_{3} \eta_{0} \varepsilon\left(q_{i}\right) d_{i j}=c_{3} \eta_{0}\left(\frac{\varepsilon^{*}-\varepsilon_{0}}{Q} q_{i}+\varepsilon_{0}\right) d_{i j}
$$

where $c_{3}$ is the unit carbon emissions cost, $\eta_{0}$ is the carbon emissions factor, $d_{i j}$ is the distance from customer $i$ to customer $j$, and $\eta_{0} \varepsilon\left(q_{i}\right)$ is the carbon emissions of the goods with the weight $q_{i}$ from customer $i$ to customer $j$.

2.1.2. The Calculation of Cost of Carbon Emissions. For the convenience of model establishment, assume that there is only one distribution center whose location is known. All the vehicles start from the distribution center and return to distribution center after delivery. The vehicles' load is known. The location and the demand of customer are known. One vehicle is for one customer.

According to the above assumption, establish the minimizing carbon emissions cost model:

$$
\begin{aligned}
\min \mathrm{CO}_{2}= & \sum_{i=0}^{L} \sum_{j=0}^{L} \sum_{k=1}^{m^{\prime}} \mathrm{CO}_{2}\left(q_{i j}\right) x_{i j k} \\
= & \sum_{i=0}^{L} \sum_{j=0}^{L} \sum_{k=1}^{m^{\prime}} c_{3} \eta_{0} \varepsilon\left(q_{i}\right) d_{i j} x_{i j k} \\
= & \sum_{i=0}^{L} \sum_{j=0}^{L} \sum_{k=1}^{m^{\prime}} c_{3} \eta_{0}\left(\frac{\varepsilon^{*}-\varepsilon_{0}}{Q} q_{i}+\varepsilon_{0}\right) d_{i j} x_{i j k} \\
= & \sum_{i=0}^{L} \sum_{j=0}^{L} \sum_{k=1}^{m^{\prime}} c_{3} \eta_{0} \varepsilon_{0} d_{i j} x_{i j k} \\
& +\sum_{i=0}^{L} \sum_{j=0}^{L} \sum_{k=1}^{m^{\prime}} c_{3} \eta_{0} \frac{\varepsilon^{*}-\varepsilon_{0}}{Q} q_{i} d_{i j} x_{i j k},
\end{aligned}
$$

where $L$ is the number of customers, $m^{\prime}$ is the number of vehicles, $q_{i}$ is the demand of the $i$ customer, $Q$ is the maximum load of the vehicles, and $k$ is the vehicle's number. 
The number of distribution center is 0 . The numbers of customers are 1,2,3 $\cdots L$. Define variables $x_{i j k}$ and $y_{k i}$ as

$$
\begin{gathered}
x_{i j k}= \begin{cases}1, & \text { vehicle } k \text { from } i \text { to } j \\
0, & \text { others }\end{cases} \\
y_{k i}= \begin{cases}1, & i \text { is sevice by vehicle } k \\
0, & \text { others }\end{cases} \\
\sum_{i=0}^{L} q_{i} y_{k i} \leq Q, \quad k \in\left[1, m^{\prime}\right] \\
\sum_{k=1}^{m^{\prime}} y_{k i}=1, \quad i \in[0, L], k \in\left[1, m^{\prime}\right] \\
\sum_{i=0}^{L} \sum_{k=1}^{m^{\prime}} x_{i j k}=1, \quad j \in[0, L], k \in\left[1, m^{\prime}\right] \\
\sum_{j=0}^{L} \sum_{k=1}^{m^{\prime}} x_{i j k}=1, \quad i \in[0, L], k \in\left[1, m^{\prime}\right] \\
\sum_{i=0}^{L} \sum_{k=1}^{m^{\prime}} x_{0 i k}=\sum_{j=0}^{L} \sum_{k=1}^{m^{\prime}} x_{j 0 k} .
\end{gathered}
$$

Formula (7) is the objective function. The first part is the carbon emissions cost caused by the vehicle's weight. The second part is the carbon emissions cost caused by the vehicle's load. Formula (10) shows that the sum of customers' demand cannot be greater than the maximum load of vehicles. Formulas (11), (12), and (13) show that one vehicle is for one customer. Formula (14) shows that vehicles start from distribution center and then return to distribution center.

2.2. Double Target Distribution Optimization Model with the Consideration of Carbon Emissions. Since the increasing pollution problems, the government considers the logistics network planning from the aspect of the whole area low carbon development to minimize the carbon emissions of the whole area. But transportation enterprises will choose the logistics lines based on the logistics network system according to their target and determine the allocation on each line. To achieve the goal of the government and the transport enterprises win-win, this paper establishes the double target distribution optimization model based on "pay attention to carbon emissions and also give consideration to economy." The basic thought of a multiobjective optimization problem is to transfer multiobject into a numerical target evaluation function, which generally uses the linear weighted sum method [14].

Firstly, the goods are delivered to the distribution center. Then, the goods are sent to each customer by through highways, waterways, air transport, and a variety of other ways. In the whole distribution process, the situation is complicated, in which there exists not only the transformation of multiple transportation modes but also multiple layers of distribution network. In a variety of transportation modes, highway transportation is the largest one of carbon dioxide emissions. Thus, for the convenience of model establishment, only consider one level of distribution network, which is from distribution center to customer delivery and only consider the highway transportation mode.

For the convenience of model establishment, make the following assumptions.

(1) Only consider the distribution center whose location is known. All the vehicles start from the distribution center. After the delivery mission, all the vehicles come back to the distribution center waiting for unified deployment.

(2) The delivery goods can be mixed. Each customer's goods will not exceed the maximum load of the vehicle.

(3) The location and demand of customers are known. One vehicle is for one customer.

(4) Load is known.

(5) The vehicle serves for each affected point service, and on the way only discharges without loading.

According to the above assumptions, establish the objective evaluation function:

$$
\begin{gathered}
\min W=\left(W_{1}, W_{2}\right)=\rho_{1} W_{1}+\rho_{2} W_{2} \\
W_{1}=\sum_{i=0}^{L} \sum_{j=0}^{L} \sum_{k=1}^{m^{\prime}} \mathrm{CO}_{2}\left(q_{i j}\right) x_{i j k}=\sum_{i=0}^{L} \sum_{j=0}^{L} \sum_{k=1}^{m^{\prime}} c_{3} \eta_{0} \varepsilon\left(q_{i}\right) d_{i j} x_{i j k}
\end{gathered}
$$

$$
\begin{aligned}
& W_{2}=c_{0} m^{\prime}+\sum_{i=0}^{L} \sum_{j=0}^{L} \sum_{k=1}^{m^{\prime}} c_{1} d_{i j} x_{i j k} \\
& +c_{2} \sum_{k=1}^{m^{\prime}}\left(\max \left\{\sum_{i=1}^{L}\left(q_{i} y_{k i}-Q\right), 0\right\}\right) \\
& \sum_{i=0}^{L} q_{i} y_{k i} \leq Q, \quad k \in\left[1, m^{\prime}\right] \\
& \sum_{k=1}^{m^{\prime}} y_{k i}=1, \quad i \in[0, L], k \in\left[1, m^{\prime}\right] \\
& \sum_{i=0}^{L} \sum_{k=1}^{m^{\prime}} x_{i j k}=1, \quad j \in[0, L], k \in\left[1, m^{\prime}\right] \\
& \sum_{j=0}^{L} \sum_{k=1}^{m^{\prime}} x_{i j k}=1, \quad i \in[0, L], k \in\left[1, m^{\prime}\right]
\end{aligned}
$$




$$
\begin{gathered}
\sum_{i=0}^{L} x_{i j k}=y_{k j}, \quad i \in[0, L], k \in\left[1, m^{\prime}\right] \\
\sum_{j=0}^{L} x_{i j k}=y_{k i}, \quad i \in[0, L], k \in\left[1, m^{\prime}\right] \\
\sum_{i=0}^{L} \sum_{k=1}^{m^{\prime}} x_{0 i k}=\sum_{j=0}^{L} \sum_{k=1}^{m^{\prime}} x_{j 0 k},
\end{gathered}
$$

where $\rho_{1}, \rho_{2}$ are the weight coefficients of the objective function, $c_{0}$ is unit vehicle cost, $c_{1}$ is unit cost of travelling distance, and $c_{2}$ is the overload punishment coefficient. Formula (15) is the objective function. The lower value the objective evaluation function has, the better the path is. Formula (16) is the evaluation function of carbon emissions. Formula (17) is the economic evaluation function including three parts. The first part is the vehicle fixed cost. The second part is the vehicle's transportation cost. The third part is the overload punishment cost. Formulas (18) to (24) are the constraint conditions. Formula (22) shows that the mission of the demand point $j$ is accomplished by the vehicle $k$ through point $i$. Formula (23) shows that the mission of the demand point $i$ is accomplished by the vehicle $k$ through point $j$. The other constraint conditions are the same as the minimum carbon emissions cost distribution optimization model.

According to the degree of pollution, the air pollution index is divided into five levels: top grade, good, light pollution, moderate pollution, and high level of pollution. Top level and good level include normal activities. Light pollution includes long-term exposure to this level air, vulnerable groups' symptoms will be slightly worse, and healthy people will have irritation symptoms. Moderate pollution includes contacting with the air after a certain period of time, symptoms of the people with heart disease and pulmonary disease significantly will increase, exercise tolerance decreases, and common symptoms happen in healthy people. In high level of pollution, healthy exercise tolerance is reduced and it has obvious symptoms and diseases. According to different level of air pollution index, the values of weight coefficients of evaluation function $\rho_{1}, \rho_{2}$ are also different. When the air pollution degree is good, ignore the influence of the carbon emissions cost, which is $\rho_{1}=0, \rho_{2}=1$. When the air pollution is light pollution, first consider the economic then consider carbon emissions, which is $\rho_{1} \leq \rho_{2}$. When the air pollution is moderately severe pollution, put the emission reduction and energy saving in the first place with carbon emissions as the first goal and economic target as the balance, which is $\rho_{1}>\rho_{2}$.

\section{Methods}

3.1. Basic Ant Colony Algorithm. Scientists, who study social insect behavior characteristic, found that the insect at the community level of cooperation is basically self-organizing. This kind of collective behavior produced by the social organism, which is a kind of swarm intelligence, catches the eyes of many researchers in the fields of management science and engineering. Ant colony algorithm is a typical example of the use of swarm intelligence to solve combinatorial optimization problems. Ant colony algorithm as a new bionic evolutionary algorithm is published by Dorigo and Gambardella [15]. The algorithm imitates ants foraging behavior, according to the heuristic idea, which is caused by entrainment of pheromones, gradually converging to the global optimal solution of the problem. So far, the ant colony algorithm has been used to solve traveling salesman problem, quadratic assignment problem, vehicle routing problem, dynamic vehicle scheduling problem, and network routing optimization problem.

Ant colony algorithm is a kind of parallel algorithm. The searching process is not starting from a point, but from the multiple points simultaneously. The distributed parallel model greatly improves the whole operation efficiency and quick reaction capability of the algorithm, which not only increases the reliability of the algorithm but also makes the algorithm have a stronger global searching ability. Ant colony algorithm has positive feedback characteristics, which can strengthen the optimal solution of pheromones to speed up the convergence speed of the algorithm. Ant colony algorithm has robustness, whose result is not dependent on the initial route choice, and does not need manual adjustment in the process. Ant colony algorithm is easily combined with other heuristic algorithms to improve the algorithm performance. Although the ant colony algorithm has many advantages, there are still some defects such as long searching time, slow convergence speed, slow evolution, stagnation happening easily, and precocious phenomena.

Assume that there are $n$ cities. The distance between any two cities $i$ and $j$ is $d_{i j}(i, j=1,2, \ldots, n) . b_{i}(t)$ is the number of ants at time $t$ at city $i . m=\sum_{i=1}^{n} b_{i}(t)$ is the total number of ants. $\tau_{i j}(t)$ is the pheromone at time $t$ on the line $i j$. At time $t=0$, every path has the same pheromone strength. $\Delta \tau_{i j}(t)=$ 0 .

With time passing by, the new pheromone is added and old pheromones evaporate. $\rho$ is the pheromone volatilization coefficient which indicates pheromones volatile speed. When all the ants accomplish one travel, pheromone on every path is

$$
\begin{gathered}
\tau_{i j}(t+1)=(1-\rho) \tau_{i j}(t)+\Delta \tau_{i j}(t) \\
\Delta \tau_{i j}(t)=\sum_{k=1}^{m} \Delta \tau_{i j}^{k}(t)
\end{gathered}
$$

where $\Delta \tau_{i j}(t)$ is the pheromone increment on the path $i j$. At the beginning, $\Delta \tau_{i j}(0)=0 . \Delta \tau_{i j}^{k}(t)$ is the pheromone released by ant $k$ on the path $i j$, which is determined by the ants performance. The more the paths are, the more the pheromone is:

$$
\Delta_{i j}^{k}(t)= \begin{cases}\frac{Q}{L_{k}} & \begin{array}{l}
\text { section } k \text { of ants pass edge } \\
i j \text { in the course of this tour } \\
\text { else, }
\end{array}\end{cases}
$$


where $Q$ is constant and $L_{k}$ is the path length of the ant $k$. The transition probability of ant $k$ from city $i$ to city $j$ is

$$
P_{i j}^{k}= \begin{cases}\frac{\left[\tau_{i j}(t)\right]^{\alpha} \cdot\left[\eta_{i j}(t)\right]^{\beta}}{\sum_{s \in \text { allowed }_{k}}\left[\tau_{i s}(t)\right]^{\alpha} \cdot\left[\eta_{i s}(t)\right]^{\beta}} & j \in \text { allowed }_{k} \\ 0 & \text { others, }\end{cases}
$$

where allowed a $_{k}=(1,2, \ldots, n)-$ tabu $_{k}$ indicates that the city collection ant $k$ can choose currently. $\operatorname{tabu}_{k}(k=1,2, \ldots, m)$ is the taboo table of ant $k$, which indicates the cities ant $k$ has passed by to show the memory of ants. $\eta_{i j}(t)$ is prior knowledge visibility. In the TSP problem, it is the heuristic information from one city moved to another city, which is generally $\eta_{i j}(t)=1 / d_{i j}$. $\alpha$ is the importance of the residual information on the path $i j$. $\beta$ is the importance of the heuristic information.

The basic ant colony algorithm to achieve the process is that $m$ ants start from one certain city at the same time to choose the next city based on Formula (28), which indicates that ants prefer visiting the path with higher intensity of pheromone. The passed cities will be put into tabu $\mathrm{b}_{k}$. After all ants finish one travel, renew the pheromone on each path based on Formula (25) to Formula (27). Repeat the above processes until termination condition is established.

3.2. DNA-Ant Colony Algorithm Solution Model. The numerous studies of ant colony algorithm have shown its significance in the optimization combination problem, but there are still some shortcomings, such as seeking to local optimal solution rather than the global optimal solution and convergence lag. In particular, for the selection of basic ant colony algorithm parameters, there is no theoretical derivation but relying on the results of experiments. The selection of ant colony algorithm parameters is directly related to the effectiveness of the algorithm's solution. If the parameter selection is improper, it will seriously affect the performance of the ant colony algorithm. DNA-ant colony algorithm controls the parameter selection by the crossover and mutation idea of DNA algorithm to optimize the performance of ant colony algorithm, which will overcome the shortcomings of ant colony algorithm to improve the convergence rate and search the global optimal solution.

DNA, the so-called deoxyribonucleic acid, is the most important biological macromolecules of organisms in the nature and the main genetic materials for all creatures. The discovery of DNA double helix structure marks the development of biological science which has entered the phase of molecular biology. DNA is a kind of high molecular compound, which is the basic unit of DNA nucleotides. Each deoxyribonucleotide is composed of a molecular phosphate, molecular DNA nucleotides, and a molecule nitrogenous base. Nitrogenous base includes adenine deoxynucleotide (A), guanine oligodeoxynucleotides $(\mathrm{G})$, cytosine deoxyribonucleotide $(\mathrm{C})$, and thymidine nucleotide $(\mathrm{T})$. Modern molecular biology believes that DNA is the main material basis of biological inheritance which stored the genetic information. It transfers genetic information from parent to offspring by self-copy transfer and generates the RNA transcription (ribonucleic acid) to translate into specific proteins to control the phenomenon of life [16-18]. DNA molecule with the double helix structure is circled by the two parallel deoxynucleotides long chain. Deoxyribose and phosphate in DNA molecule alternately link and arrange on the outer side constituting the basic skeleton. The bases on the two chains are linked together by hydrogen bonds forming base pairs. Base pairs follow the principle of complementary base pairing, namely, purines and pyrimidines matching; that is, adenine (A) and thymine (T) must be matched and guanine $(\mathrm{G})$ and cytosine $(\mathrm{C})$ must be matched. Although deoxyribose and phosphate arrange stably on the deoxyribonucleotide long chains, the order of base pairs is protean on the long chain. There are only four bases and two methods of four types of the four bases to form the DNA molecules, but different orders of base pairs constitute a wealth of information [19].

The crossover and mutation in DNA algorithm is different from genetic algorithm. Crossover and mutation in DNA algorithm is based on gene level with a different encoding method, which is two digits binary encoding instead of unit binary encoding. The crossover operation of DNA algorithm is based on the two-point crossover method with a certain probability $p_{c}$, which means that a part of bases swaps randomly in the deoxyribonucleotide long chains to form new deoxyribonucleotide long chains (see Figure 11).

Transform coding method of DNA algorithm into two binary coding method can be recognized by computers, which is A-00, T-01, C-10, G-11, and 00 with 01 and 10 with 11 (see Figure 12).

Mutation of DNA algorithm is based on purine replacing purine and pyrimidine replacing pyrimidine, with A changing into $\mathrm{G}$ and $\mathrm{C}$ changing into T. Bases correspond to binary machines coding method, with 00 changing with 11 , and 10 changing with 01 . In the mutation, the base sequences mutation operates in a certain probability $p_{m}$ (see Figure 13).

DNA-ant colony algorithm optimizes the parameters $\alpha, \beta, \rho$ of the basic ant colony algorithm based on the crossover and mutation ideas of DNA algorithm to solve the low carbon logistics route optimization problems. The solution processes of low carbon logistics route optimization based on DNA-ant colony algorithm is as shown in Figure 1. The pseudocode of low carbon logistics route optimization based on DNA-Ant colony algorithm is as follows.

(1) The basic ant colony algorithm parameters initialization is as follows:

$$
\begin{aligned}
& N C=0(N C \text { is the number of iterations }) \\
& \text { Load }=0(\text { Load is the vehicle load }) \\
& \left.\tau_{i j}(0)=0 \text { (the pheromone on branch } i j \text { is } 0\right) .
\end{aligned}
$$

(2) The DNA ant colony algorithm parameters initialization is as follows:

DNA_NUM $=10$ (DNA_NUM is the number of updating generation of DNA algorithm); $\alpha(1, N U M)$ ( $a$ is importance matrix of the residual information); 


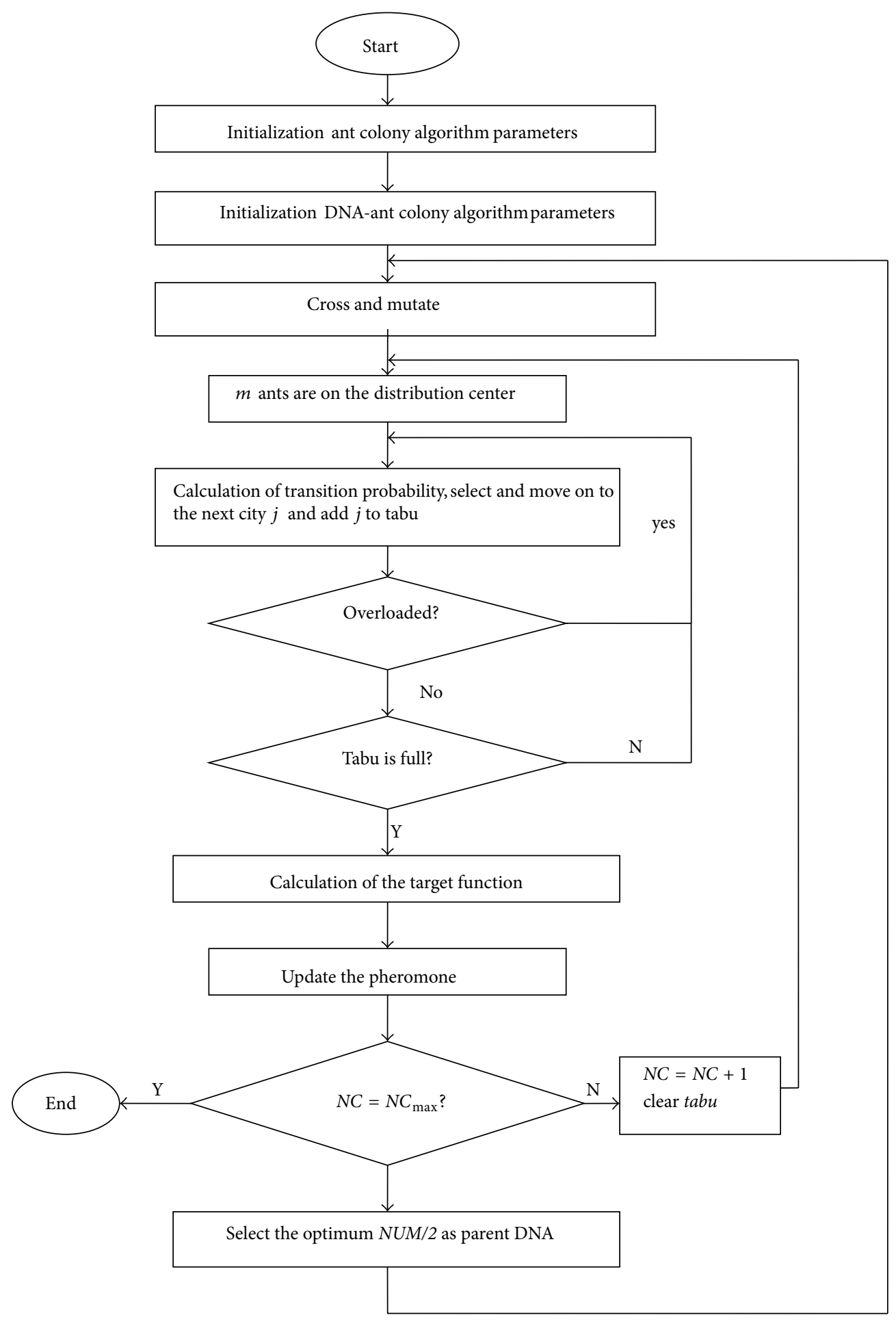

FIGURE 1: The model solution flow chart of DNA-ant colony algorithm.

$\beta(1, N U M)(\beta$ is the importance matrix of the inspiring pheromone);

$\rho(1, N U M)$ ( $\rho$ is the matrix of pheromone volatilization coefficient); $p_{c}=0.6\left(p_{c}\right.$ is the crossover probability of DNA algorithm);

$p_{m}=0.08\left(p_{m}\right.$ is the mutation probability of DNA algorithm). 
(3) Operate crossover and mutation of DNA algorithm are as follows:

for 1 to DNA_NUM do;

repeat Steps (3) (8);

operate crossover and mutation of DNA algorithm;

for 1 to $N U M$ do;

repeat Steps (4) (7).

(4) Put $m$ ants at the distribution center. The number of distribution center 1 in the array tabu to form the array $\operatorname{tabu}(1)$ is as follows:

$$
\begin{aligned}
& \text { while } N C<N C_{\max } \\
& \text { for } i=1 \text { to } m \text { do; } \\
& J=\{1,2.3 \ldots n\}-\operatorname{tabu}(1)(J \text { is the matrix of the } \\
& \text { cities will be visited). }
\end{aligned}
$$

(5) $k=k+1$ :

calculate the transition probability of ants according to Formula (28);

Load $=$ Load + Load_server $(k)$;

if Load $\leq$ Load_max;

ant $i$ goes to the next City $j$. Choose and move to the next City $j$ and put $j$ into array tabu;

else

ant $i$ returns to distribution center and put distribution center with number 1 into array tabu;

Load $=0$;

repeat Step (5) until all the cities have travelled through and then check whether tabu is full. If not, return to Step (5). Otherwise, go on to Step (6).

(6) for $i=1$ to $m$ do:

calculate the path length $l$ to solve the objective function (the values of minimum carbon emissions cost function or the objective evaluation function) and record the current best solution. Update the pheromone based on the formula (25).

(7) if $N C<N C_{\max }$ :

$$
N C=N C+1
$$

and then clean up tabu and return to Step (4).

(8) Choose the better $N U M / 2$ as the parent DNA to operate the crossover and mutation. Get the new $\alpha, \beta, \rho$ parameter matrices, and return to Step (3).

\section{Results and Discussion}

Assume the distribution center has 16 customers whose coordinate is $(0,0)$. Table 1 is the demand of each customer. Table 2 is the coordinate of each customer. The maximum load of each vehicle is 75 tons. In the simulation, set $c_{0}=$ $0, c_{1}=1, c_{2}=\infty$. The unit distance fuel cost of empty car and full car is $\varepsilon_{0}=1$ and $\varepsilon^{*}=2$. The unit carbon emissions cost is $c_{3}=0.3$. The emission factor is $\eta=2.61$ [20]. The distances between each customer and distribution center can be calculated by Formula (30):

$$
d_{i j}=\sqrt{\left(x_{i}-x_{j}\right)^{2}+\left(y_{i}-y_{j}\right)^{2}} \text {. }
$$

Table 3 shows the 10 results by using the basic ant colony algorithm to solve the minimum carbon emissions cost model. Table 4 shows the 10 results by using the DNA-ant colony algorithm to solve the minimum carbon emissions cost model. Comparing Table 3 with Table 4 we can find the following.

(1) Carbon emissions cost: the minimum carbon emissions cost of basic ant colony algorithm is 426.5, and the cost of DNA-ant colony algorithm is 398.8 . The DNA-ant colony algorithm saves $6.4 \%$ of minimum carbon emissions cost compared with basic ant colony algorithm. The average carbon emissions cost of basic ant colony algorithm is 546.2. The average cost of DNA-Ant colony algorithm is 470.34 . For the average carbon emissions cost, the DNA-ant colony algorithm saves $13.8 \%$ compared with basic ant colony algorithm. Thus, for the solution of minimum carbon emissions cost distribution model, DNA-ant colony algorithm can find the path with less carbon emissions cost, which is better for environmental protection.

(2) The number of final generation: the average number of final generation of basic ant colony algorithm is 133.7. The average number of final generation of DNAant colony algorithm is 81 . From the average number of final generation, we can find that the DNA-ant colony algorithm has a better convergence.

(3) The difference with minimum carbon emissions cost: the average difference between basic ant colony algorithm and minimum carbon emissions cost is 119.7. The average difference between DNA-ant colony algorithm and minimum carbon emissions cost is 71.54. From the difference with minimum carbon emissions cost, we can find that the DNA-Ant colony algorithm is more stable in the process of search minimum carbon emissions.

Figure 2 is the distribution path of basic ant colony based on the minimum carbon emissions cost model. The processes are as follows:

Distribution Center $\rightarrow$ Customer13 $\rightarrow$ Customer10 $\rightarrow$ Customerl1 $\rightarrow$ Distribution Center; 
TABLE 1: Demand of customer.

\begin{tabular}{|c|c|c|c|c|c|c|c|c|c|c|c|c|c|c|c|c|}
\hline Customer & 1 & 2 & 3 & 4 & 5 & 6 & 7 & 8 & 9 & 10 & 11 & 12 & 13 & 14 & 15 & 16 \\
\hline Demand & 15 & 18 & 20 & 8 & 15 & 10 & 25 & 30 & 17 & 6 & 2 & 24 & 19 & 20 & 7 & 1 \\
\hline
\end{tabular}

TABLE 2: Coordinate of customer.

\begin{tabular}{|c|c|c|c|c|c|c|c|c|c|c|c|c|c|c|c|c|}
\hline Customer & 1 & 2 & 3 & 4 & 5 & 6 & 7 & 8 & 9 & 10 & 11 & 12 & 13 & 14 & 15 & 16 \\
\hline$X$ & 2 & 8 & 18 & 34 & -25 & 35 & 42 & -10 & -8 & -12 & -32 & 28 & -18 & -9 & -18 & 8 \\
\hline Y & 8 & 33 & 20 & 28 & 15 & -5 & 10 & 20 & 10 & -32 & -40 & 7 & 0 & 25 & 8 & 10 \\
\hline
\end{tabular}

TABLE 3: The results of basic ant colony algorithm (minimum carbon emissions cost).

\begin{tabular}{lccccccccccc}
\hline No. & 1 & 2 & 3 & 4 & 5 & 6 & 7 & 8 & 9 & $\mathbf{1 0}$ & Ave. \\
\hline Carbon emissions cost & 572.3 & 544.1 & 580.9 & 592.6 & 572.5 & 544.2 & 520.7 & 559.9 & 548.3 & $\mathbf{4 2 6 . 5}$ & 546.2 \\
Vehicles & 4 & 4 & 4 & 4 & 4 & 4 & 4 & 4 & 4 & 4 & 4 \\
End iteration & 68 & 180 & 144 & 140 & 188 & 79 & 193 & 182 & 67 & 96 & 133.7 \\
Deviations & 145.8 & 117.6 & 154.4 & 166.1 & 146 & 117.7 & 94.2 & 133.4 & 121.8 & 0 & 119.7 \\
\hline
\end{tabular}

TABLE 4: The results of DNA-ant colony algorithm (minimum carbon emissions cost).

\begin{tabular}{lccccccccccc}
\hline No. & 1 & 2 & 3 & 4 & 5 & 6 & 7 & 8 & 9 & $\mathbf{1 0}$ & Ave. \\
\hline Carbon emissions cost & 516.2 & 444.6 & 493.6 & 489.1 & 461.3 & 484.4 & 456.4 & 485.3 & 473.7 & $\mathbf{3 9 8 . 8}$ & 470.34 \\
Vehicles & 4 & 4 & 4 & 4 & 4 & 4 & 4 & 4 & 4 & 4 & 4 \\
End iteration & 174 & 144 & 79 & 16 & 16 & 46 & 65 & 175 & 34 & 61 & 81 \\
Deviations & 117.4 & 45.8 & 94.8 & 90.3 & 62.5 & 85.6 & 57.6 & 86.5 & 74.9 & 0 & 71.54 \\
\hline
\end{tabular}

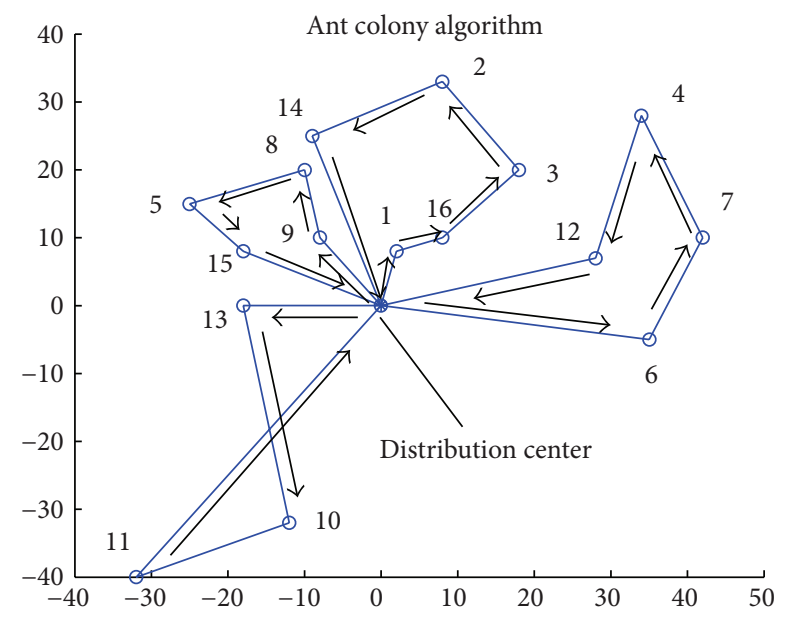

FIGURE 2: Distribution path basic ant colony algorithm (minimum carbon emissions cost).

Distribution Center $\rightarrow$ Customerl $\rightarrow$ Customer16 $\rightarrow$ Customer3 $\rightarrow$ Customer2 $\rightarrow$ Customer14 $\rightarrow$ Distribution Center;

Distribution Center $\rightarrow$ Customer9 $\rightarrow$ Customer8 $\rightarrow$ Customer $5 \rightarrow$ Customer15 $\rightarrow$ Distribution Center;

Distribution Center $\rightarrow$ Customer6 $\rightarrow$ Customer7 $\rightarrow$ Customer $4 \rightarrow$ Customer12 $\rightarrow$ Distribution Center.
Figure 3 is the distribution path of DNA-Ant colony based on the minimum carbon emissions cost model. The processes are as follows:

Distribution Center $\rightarrow$ Customer10 $\rightarrow$ Customer11 $\rightarrow$ Customer13 $\rightarrow$ Distribution Center;

Distribution Center $\rightarrow$ Customer6 $\rightarrow$ Customer7 $\rightarrow$ Customer $4 \rightarrow$ Customer12 $\rightarrow$ Distribution Center;

Distribution Center $\rightarrow$ Customer8 $\rightarrow$ Customer14 $\rightarrow$ Customer $5 \rightarrow$ Customer15 $\rightarrow$ Distribution Center;

Distribution Center $\rightarrow$ Customer $\rightarrow$ Customer16 $\rightarrow$ Customer3 $\rightarrow$ Customer2 $\rightarrow$ Customer9 $\rightarrow$

Distribution Center.

Figure 4 is the optimization curves of minimum carbon emissions cost. From the figure, we can find that DNA-Ant colony algorithm has a better effectiveness in the process of searching minimum carbon emissions cost. Comparing with basic ant colony algorithm, we can find the lower carbon emissions cost with a faster convergence speed.

When the air pollution level is good level, vehicles are only considered the distribution cost, and the carbon emissions cost is ignored, which means that $\rho_{1}=0, \rho_{2}=1$. At this time, the minimum value of objective function is the minimum value of distribution cost.

Table 5 shows the 10 results by using the basic ant colony algorithm to solve the double targets distribution optimization model under the top or good air pollution level condition. Table 6 shows the 10 results by using the DNAant colony algorithm to solve the double targets distribution 
TABLE 5: The results of basic ant colony algorithm (top or good air pollution level).

\begin{tabular}{lccccccccccc}
\hline No. & 1 & 2 & 3 & 4 & 5 & 6 & 7 & 8 & 9 & 10 & Ave. \\
\hline Cost & 403.1 & 402.7 & 403.9 & 404.5 & 407.5 & 405.3 & 400.7 & 405.3 & 409.5 & 407.9 & 405.04 \\
Vehicles & 4 & 4 & 4 & 4 & 4 & 4 & 4 & 4 & 4 & 4 & 4 \\
End iteration & 186 & 159 & 125 & 15 & 178 & 123 & 196 & 5 & 63 & 63 & 111.3 \\
Deviations & 2.4 & 2 & 3.2 & 3.8 & 6.8 & 4.6 & 0 & 4.6 & 8.8 & 7.2 & 4.34 \\
\hline
\end{tabular}

TABLE 6: The results of DNA-ant colony algorithm (top or good air pollution level).

\begin{tabular}{lcccccccccccc}
\hline No. & 1 & 2 & 3 & 4 & 5 & 6 & 7 & 8 & 9 & 10 & Ave \\
\hline Cost & 400 & 398 & 400.7 & $\mathbf{3 9 8}$ & $\mathbf{3 9 8}$ & 404 & $\mathbf{3 9 8}$ & 400.7 & $\mathbf{3 9 8}$ & 407.9 & 400.33 \\
Vehicles & 4 & 4 & 4 & 4 & 4 & 4 & 4 & 4 & 4 & 4 \\
End iteration & 19 & 145 & 77 & 13 & 33 & 16 & 16 & 163 & 27 & 27 & 53.6 \\
Deviations & 2 & 0 & 2.7 & 0 & 0 & 6 & 0 & 2.7 & 0 & 9.9 & 2.33 \\
\hline
\end{tabular}

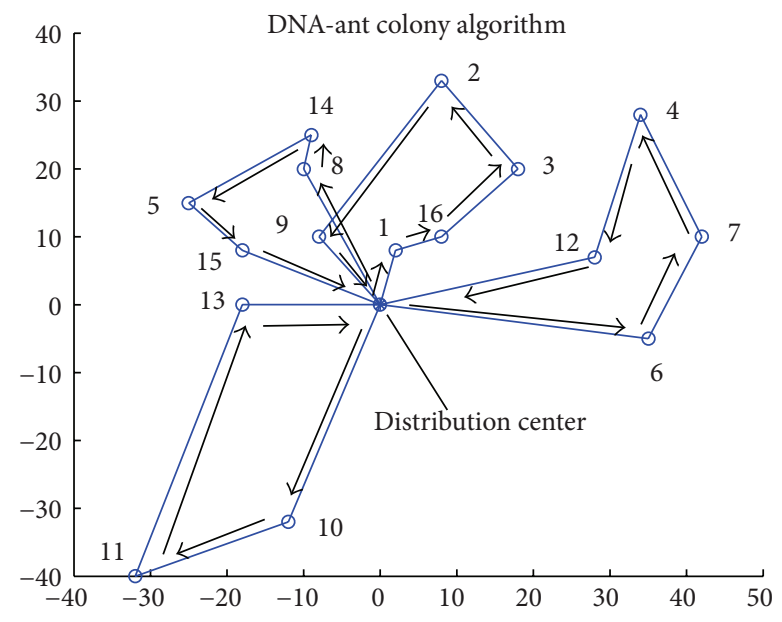

FIGURe 3: Distribution path DNA-ant colony algorithm (minimum carbon emissions cost).

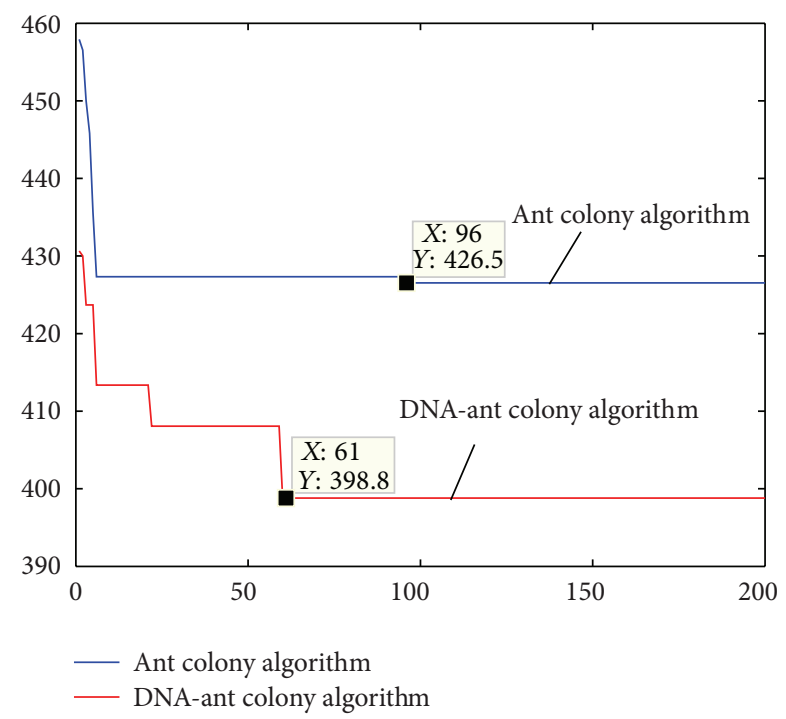

FIGURE 4: Minimum carbon emissions cost optimization curve. optimization model under the top or good air pollution level condition. Comparing Table 5 with Table 6 we can find the following.

(1) Distribution cost: the minimum distribution cost of basic ant colony algorithm is 400.7 and the cost of DNA-ant colony algorithm is 398. The DNA-ant colony algorithm saves $0.67 \%$ of minimum distribution cost comparing with basic ant colony algorithm. The average distribution cost of basic ant colony algorithm is 405.04. The average cost of DNA-ant colony algorithm is 400.33 . For the average distribution cost, the DNA-ant colony algorithm saves $1.16 \%$ compared with basic ant colony algorithm. Thus, for the good air pollution level, DNA-ant colony algorithm can find the path with less distribution cost compared with basic ant colony algorithm.

(2) The number of final generation: the average number of final generation of basic ant colony algorithm is 111.3. The average number of final generation of DNA-ant colony algorithm is 53.6. From the average number of final generation, we can find the DNA-ant colony algorithm has a better convergence speed.

(3) The difference with minimum values: the average difference between basic ant colony algorithm and minimum values is 4.34 . The average difference between DNA-ant colony algorithm and minimum values is 2.33. From the difference with minimum values, we can find that the DNA-ant colony algorithm is more stable in the process of search the best solution.

Figure 5 is the distribution path figure of basic ant colony algorithm, which is shown in Table 7. Figure 6 is the distribution path figure of DNA-Ant colony algorithm, which is shown in Table 8.

Figure 7 is the distribution cost optimization curves comparing the figure of the two algorithms. From the simulation, we can find that DNA-ant colony algorithm performances is more effective on the solution issue, which can save more distribution cost with a faster convergence speed. 


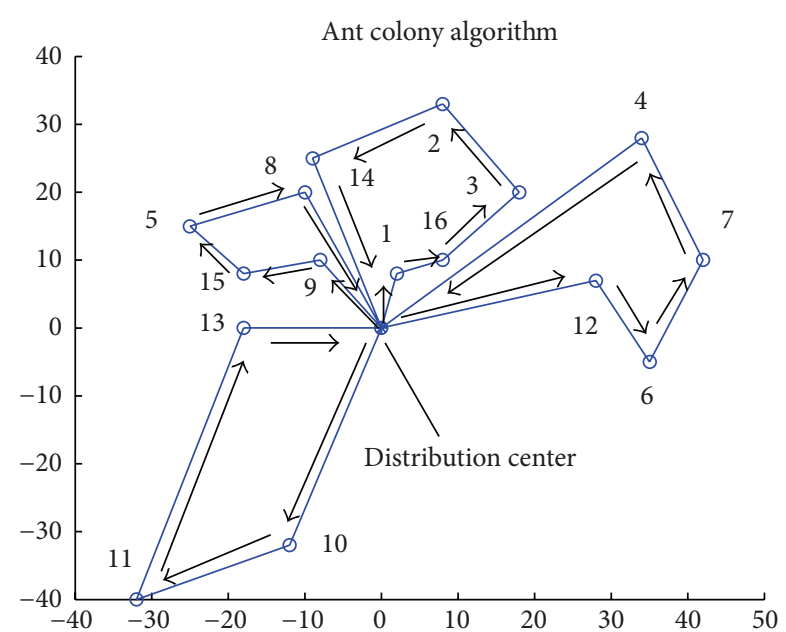

FIGURE 5: Distribution path basic ant colony algorithm (top or good air pollution level).

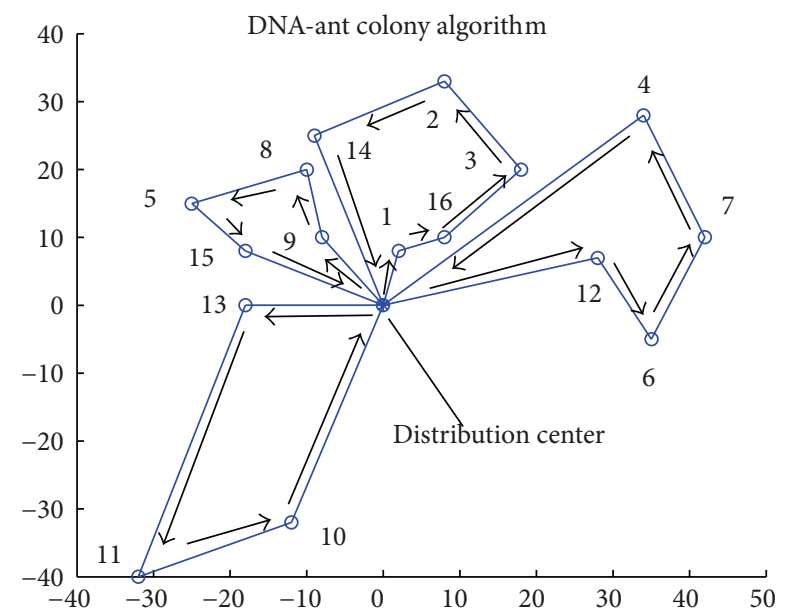

FIGURE 6: Distribution path DNA-ant colony algorithm (top or good air pollution level).

TABLE 7: The distribution path figure of basic ant colony algorithm.

\begin{tabular}{ll}
\hline Vehicle $k$ & Distribution path \\
\hline 1 & Distribution Center-10-11-13-Distribution Center \\
2 & Distribution Center-1-16-3-2-14-Distribution Center \\
3 & Distribution Center-9-15-5-8-Distribution Center \\
4 & Distribution Center-12-6-7-4-Distribution Center \\
\hline
\end{tabular}

TABLE 8: The distribution path figure of DNA-ant colony algorithm.

\begin{tabular}{ll}
\hline Vehicle $k$ & Distribution path \\
\hline 1 & Distribution Center-13-11-10-Distribution Center \\
2 & Distribution Center-1-16-3-2-14-Distribution Center \\
3 & Distribution Center-9-8-5-15-Distribution Center \\
4 & Distribution Center-12-6-7-4-Distribution Center \\
\hline
\end{tabular}

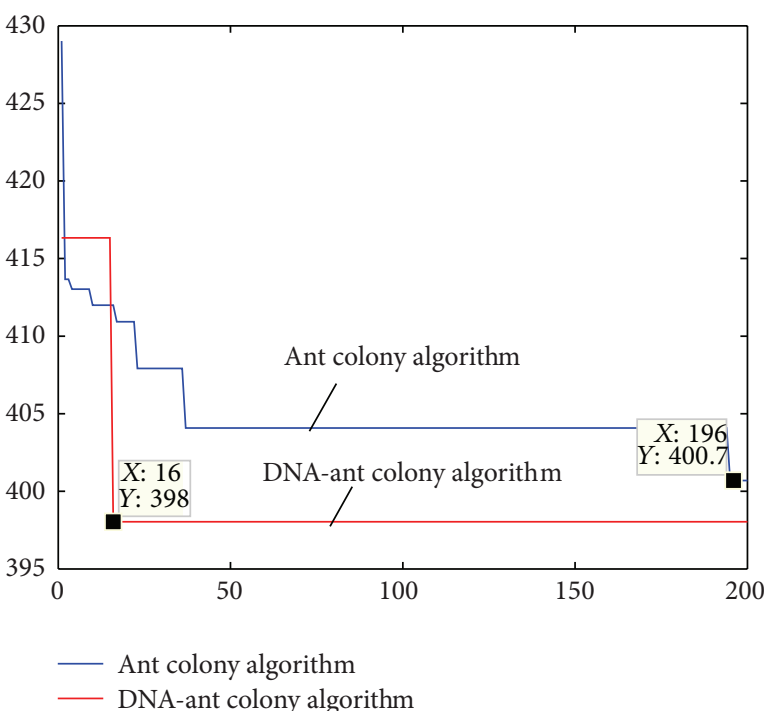

FIGURE 7: Distribution cost optimization curve (top or good air pollution level).

Assume that the air pollution level is moderate or high level pollution; set $\rho_{1}=0.8, \rho_{2}=0.2$. Table 9 shows the 10 results by using the basic ant colony algorithm to solve the double targets distribution optimization model under the moderate or high level pollution condition. Table 10 shows the 10 results by using the DNA-ant colony algorithm to solve the double targets distribution optimization model under the moderate or high level pollution condition. Comparing Table 9 with Table 10 we can find the following.

(1) Objective evaluation function value: the minimum objective evaluation function value of basic ant colony algorithm is 417.5 and the cost of DNA-ant colony algorithm is 402.6. The DNA-ant colony algorithm saves $3.5 \%$ of minimum objective evaluation function value compared with basic ant colony algorithm. The average objective evaluation function value of basic ant colony algorithm is 431.22 . The average cost of DNA-ant colony algorithm is 414.09 . For the average objective evaluation function value, the DNA-ant colony algorithm saves $3.97 \%$ compared with basic ant colony algorithm. Thus, for the moderate or high level pollution, DNA-ant colony algorithm can find the path with less objective evaluation function value to find the more effective distribution paths and reduce air pollution and distribution cost.

(2) The number of final generation: the average number of final generation of basic ant colony algorithm is 163.3. The average number of final generation of DNA-ant colony algorithm is 86.9. From the average number of final generation, we can find that the DNAant colony algorithm has a better convergence speed.

(3) The difference with minimum values: the average difference between basic ant colony algorithm and minimum values is 13.72 . The average difference between DNA-ant colony algorithm and minimum values is 
TABLE 9: The results of basic ant colony algorithm (moderate or high level pollution).

\begin{tabular}{lccccccccccc}
\hline No. & 1 & 2 & 3 & 4 & 5 & 6 & 7 & 8 & 9 & 10 & Ave. \\
\hline W & 430.3 & 422.4 & 417.5 & 423.2 & 458.4 & 433.2 & 443.4 & 437.4 & 418.4 & 428 & 431.22 \\
Vehicles & 4 & 4 & 4 & 4 & 4 & 4 & 4 & 4 & 4 & 4 \\
End iteration & 160 & 175 & 193 & 150 & 155 & 162 & 182 & 161 & 163 & 132 & 163.3 \\
Deviations & 12.8 & 4.9 & 0 & 5.7 & 40.9 & 15.7 & 25.9 & 19.9 & 0.9 & 10.5 & 13.72 \\
\hline
\end{tabular}

TABLE 10: The results of DNA-ant colony algorithm (moderate or high level pollution).

\begin{tabular}{lccccccccccc}
\hline No. & 1 & 2 & 3 & 4 & 5 & 6 & 7 & 8 & 9 & 10 & Ave. \\
\hline W & 418.6 & $\mathbf{4 0 2 . 6}$ & $\mathbf{4 0 2 . 6}$ & 409 & 412.6 & 428.7 & 414.8 & 421.1 & 415.8 & 415.1 & 414.09 \\
Vehicles & 4 & 4 & 4 & 4 & 4 & 4 & 4 & 4 & 4 & 4 & 4 \\
End iteration & 126 & 30 & 133 & 68 & 20 & 133 & 26 & 46 & 131 & 156 & 86.9 \\
Deviations & 16 & 0 & 0 & 6.4 & 10 & 26.1 & 12.2 & 18.5 & 13.2 & 12.5 & 11.49 \\
\hline
\end{tabular}

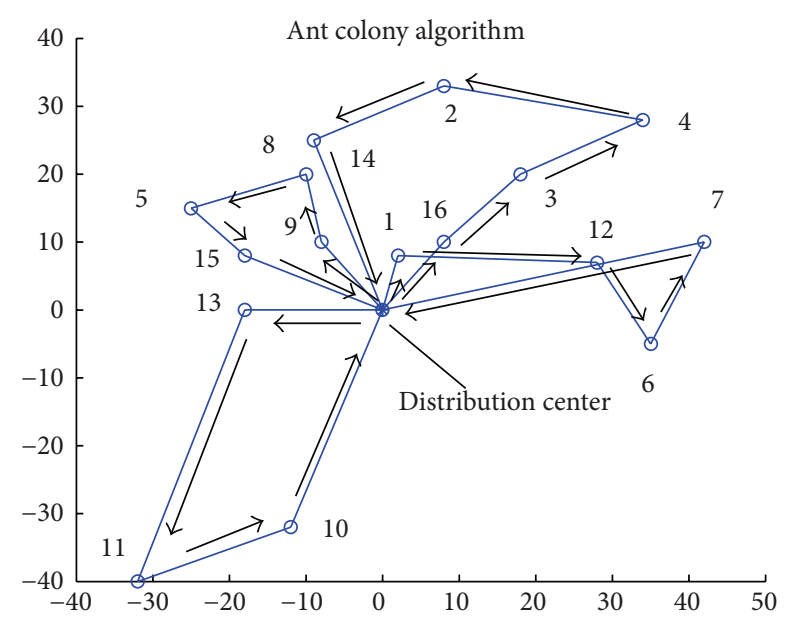

FIGURE 8: Distribution path basic ant colony algorithm (moderate or high level pollution).

11.49. From the difference with minimum values, we can find that the DNA-ant colony algorithm is more stable in the process of search the best solution.

Figure 8 is the distribution path of basic ant colony under moderate or high level pollution condition. The processes are as follows:

Vehicle 1: Distribution Center $\rightarrow$ Customer13 $\rightarrow$ Customer11 $\rightarrow$ Customer10 $\rightarrow$ Distribution Center;

Vehicle 2: Distribution Center $\rightarrow$ Customer9 $\rightarrow$ Customer8 $\rightarrow$ Customer $5 \rightarrow$ Customer15 $\rightarrow$ Distribution Center;

Vehicle 3: Distribution Center $\rightarrow$ Customer16 $\rightarrow$ Customer3 $\rightarrow$ Customer $4 \rightarrow$ Customer $2 \rightarrow$ Customer14 $\rightarrow$ Distribution Center;

Vehicle 4: Distribution Center $\rightarrow$ Customerl $\rightarrow$ Customer12 $\rightarrow$ Customer6 $\rightarrow$ Customer7 $\rightarrow$ Distribution Center.

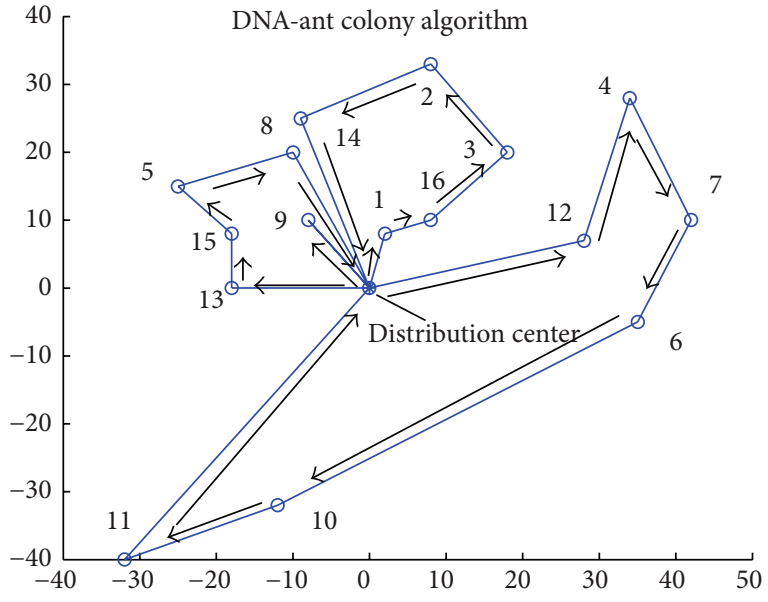

FIGURE 9: Distribution path DNA-ant colony algorithm (moderate or high level pollution).

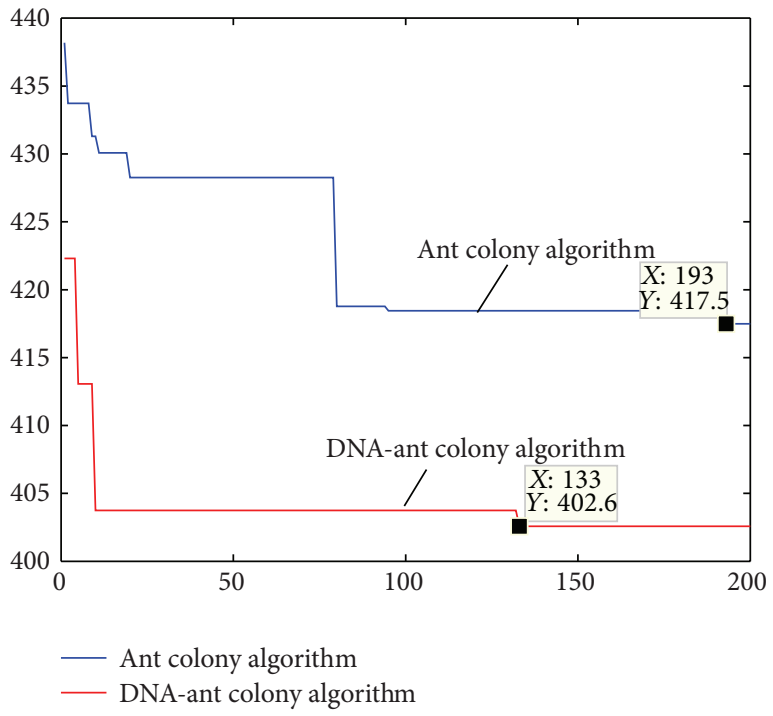

FIgURE 10: Distribution cost optimization curve (moderate or high level pollution). 


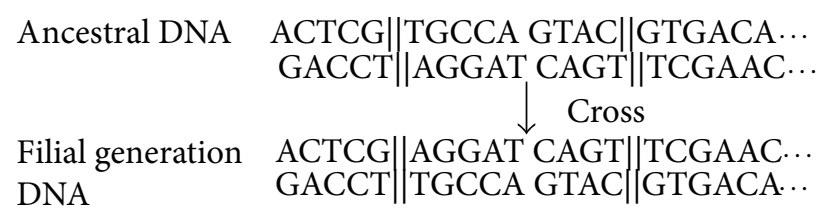

FIGURE 11

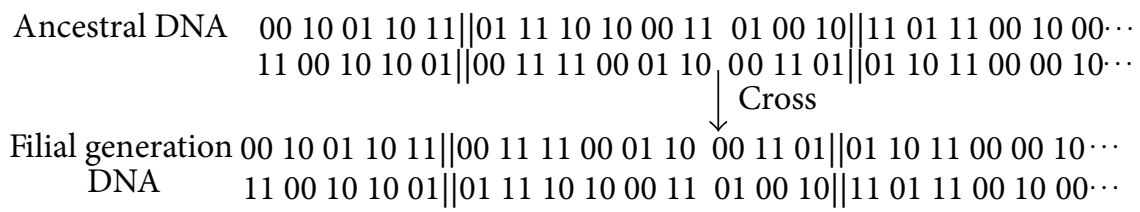

FIGURE 12

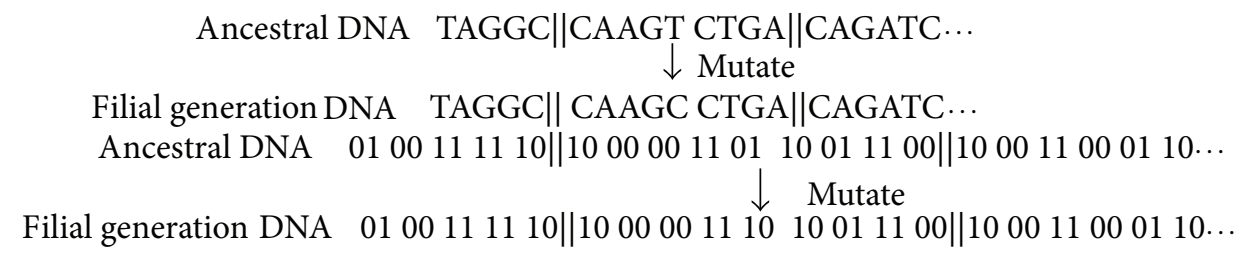

FIGURE 13

Figure 9 is the distribution path of DNA-ant colony under moderate or high level pollution condition. The processes are as follows:
Vehicle 1: Distribution Center $\rightarrow$ Customerl $\rightarrow$ Customer16 $\rightarrow$ Customer3 $\rightarrow$ Customer $2 \rightarrow$ Customer14 $\rightarrow$ Distribution Center;
Vehicle 2: Distribution Center $\rightarrow$ Customer13 $\rightarrow$ Customer15 $\rightarrow$ Customer $5 \rightarrow$ Customer8 $\rightarrow$ Distribution Center;
Vehicle 3: Distribution Center $\rightarrow$ Customer12 $\rightarrow$ Customer $4 \rightarrow$ Customer7 $\rightarrow$ Customer6 $\rightarrow$ Customer10 $\rightarrow$ Customer11 $\rightarrow$ Distribution Center;
Vehicle 4: Distribution Center $\rightarrow$ Customer9 $\rightarrow$ Distribution Center.

Figure 10 is the optimization curve of objective evaluation function best value. From the figure, we can find that, under the moderate or high level pollution condition, DNA-ant colony algorithm can find the lower objective evaluation function value to get a faster convergence speed than the basic ant colony algorithm.

\section{Conclusions}

In this paper, starting from the actual requirements of low carbon logistics, microscopic quantitative analysis was used for low carbon logistics. The minimum cost of carbon emissions model and the double target distribution optimization model with considering the cost of carbon emissions were established to find the reasonable distribution routes to achieve energy conservation and emissions reduction based on the solution of DNA-ant colony algorithm. According to the simulation of MATLAB, DNA-ant colony algorithm had a better effectiveness than the basic ant colony algorithm on the issue of low carbon logistics distribution route optimization. But this is the preliminary research on the low carbon logistics distribution route optimization problem. It is the exploration stage for low carbon logistics distribution route optimization model. The models are established based on the ideal situation without consideration of many complex factors and real situations in the constraints of the models. In future study, there is a to optimize the model to make the model more accord with the actual needs.

\section{Conflict of Interests}

The authors declare that there is no conflict of interests regarding the publication of this paper.

\section{Acknowledgment}

This work was supported by Soft Science Research Project in Shanxi Province (no. 2010041077-3).

\section{References}

[1] X. Xu, "Research on construction and characteristics of low carbon logistics system," Commercial Times, no. 10, pp. 23-24, 2011. 
[2] X.-Y. Liu, "Analysis of the development of low-carbon logistics based on a low-carbon economy," in Proceedings of the International Conference on Low-Carbon Transportation and Logistics and Green Buildings, pp. 673-679, 2013.

[3] H.-J. Wu and S. Dunn, "Environmentally responsible logisties systems," International Journal of Physical Distribution and Logistics Management, vol. 25, no. 2, pp. 20-38, 1995.

[4] J. P. Rodrigue, B. Slake, and C. Comtois, "Green logistics," in The Handbook of Logistics and Supply-Chain Management, A. M. Brewer, K. J. Button, and D. A. Hensher, Eds., Paragon Elsevier, London, UK, 2001.

[5] A. McKinnon, "Green logistics: the carbon agenda," Electronic Scientific Journal of Logistics, vol. 6, no. 3, pp. 1-9, 2010.

[6] J. Liu and K. Han, "Establishment of logistics system in lowcarbon economy," Logistics Technology, no. 13, pp. 77-79, 2013.

[7] X. Lin, "China-ASEAN and Guangxi multiple-regions cooperative low-carbon logistics internet of things service system hidden Markov optimization model," Advances in Intelligent and Soft Computing, vol. 162, pp. 65-72, 2012.

[8] M. Yang and Y. Tian, "Establishment and application of logistics enterprises'low-carbon factors index system," in Proceedings of the 2nd International Conference on Logistics, Informatics and Service Science (LISS '12), pp. 401-407, July 2012.

[9] S. Cholette and K. Venkat, "The energy and carbon intensity of wine distribution: a study of logistical options for delivering wine to consumers," Journal of Cleaner Production, vol. 17, no. 16, pp. 1401-1413, 2009.

[10] I. Harris, M. Naim, A. Palmer, A. Potter, and C. Mumford, "Assessing the impact of cost optimization based on infrastructure modelling on $\mathrm{CO}_{2}$ emissions," International Journal of Production Economics, vol. 131, no. 1, pp. 313-321, 2011.

[11] Y. Wang, T. Lu, and C. Zhang, "Integrated logistics network design in hybrid manufacturing/remanufacturing system under low-carbon restriction," in Proceedings of the 2nd International Conference on Logistics, Informatics and Service Science (LISS '12), pp. 111-121, July 2012.

[12] H. Huang, "A study of developing Chinese low carbon logistics in the new railway period," in Proceedings of the International Conference on E-Product E-Service and E-Entertainment (ICEEE '10), pp. 635-638, November 2010.

[13] S. Qin, Research on fuel consumption minimized vehicle routing problem [M.S. thesis], Tsinghua University, Beijing, China, 2011.

[14] Y. Le and P. Zhen, "Path design of emergency medical supplies transport," Logistics Technology, vol. 27, no. 11, pp. 84-86, 2008.

[15] M. Dorigo and L. M. Gambardella, "Ant colony system: a cooperative learning approach to the traveling salesman problem," IEEE Transactions on Evolutionary Computation, vol. 1, no. 1, pp. 53-66, 1997.

[16] C. Wu, DNA algorithm of the minimum set covering problem in wireless sensor networks research [M.S. thesis], East China University of Science and Technology, Shanghai, China, 2010.

[17] X. Chen, DNA genetic algorithm and its application [Ph.D. thesis], Zhejiang University, Zhejiang, China, 2010.

[18] R. J. Lipton, "DNA solution of hard computational problems," Science, vol. 268, no. 5210, pp. 542-545, 1995.

[19] H. Zhu, Vehicles scheduling problemwith DNA algorithm research [M.S. thesis], Harbin University of Science and Technology, Harbin, China, 2003.

[20] L. V. Pin, "Study of logistics network optimization model considering carbon emissions," Application Research of Computers, vol. 30, no. 10, pp. 2977-2980, 2013. 


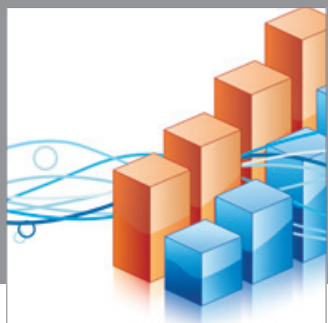

Advances in

Operations Research

mansans

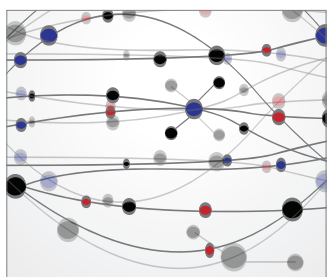

The Scientific World Journal
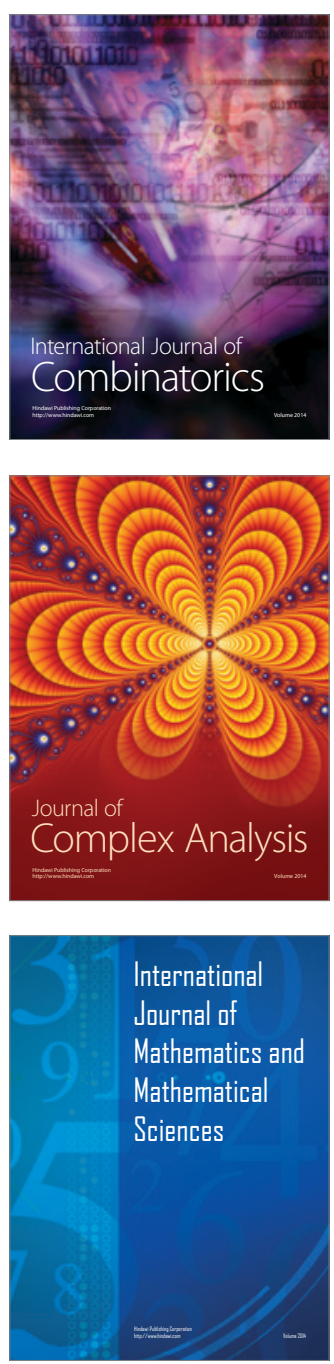
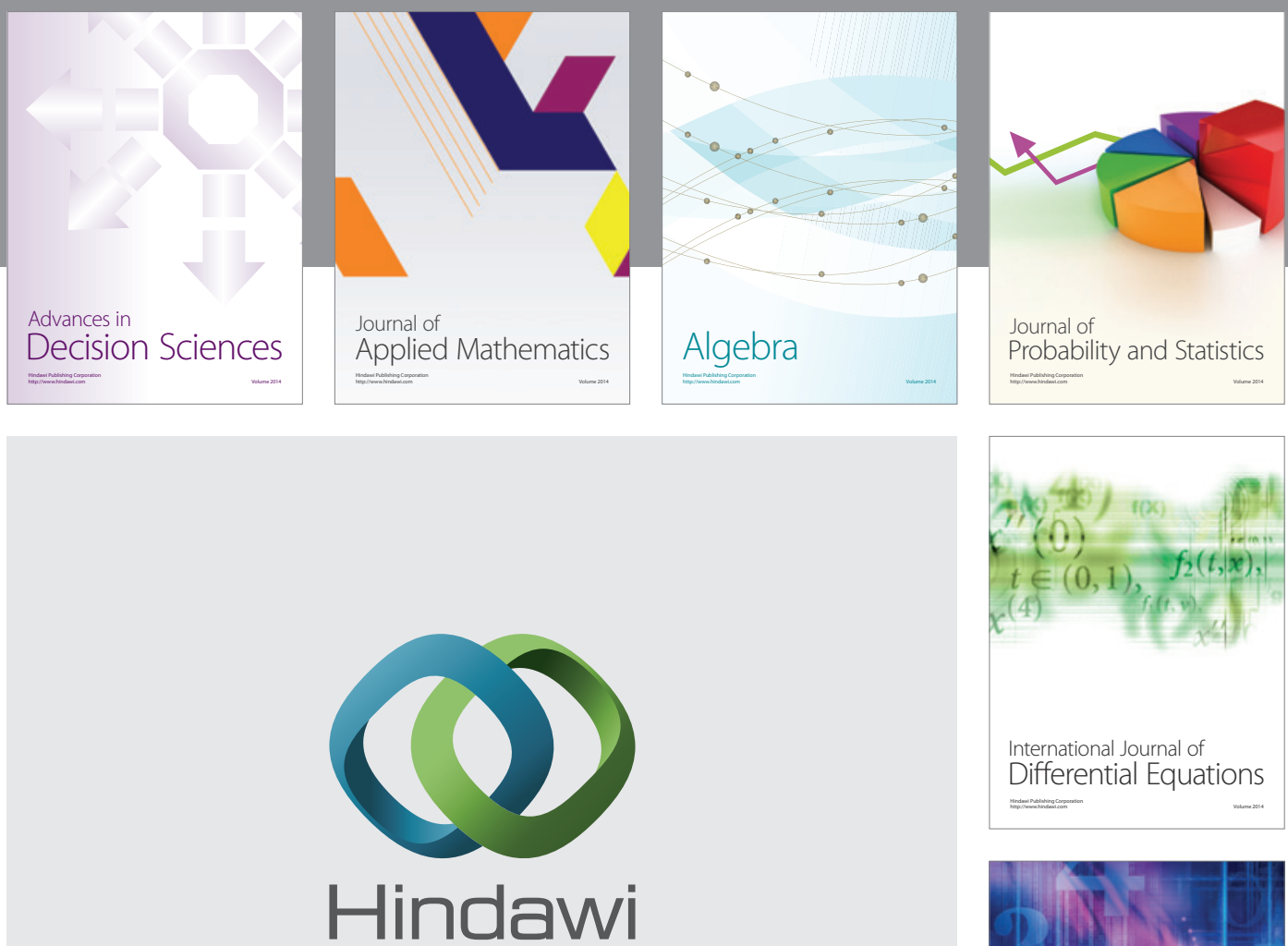

Submit your manuscripts at http://www.hindawi.com
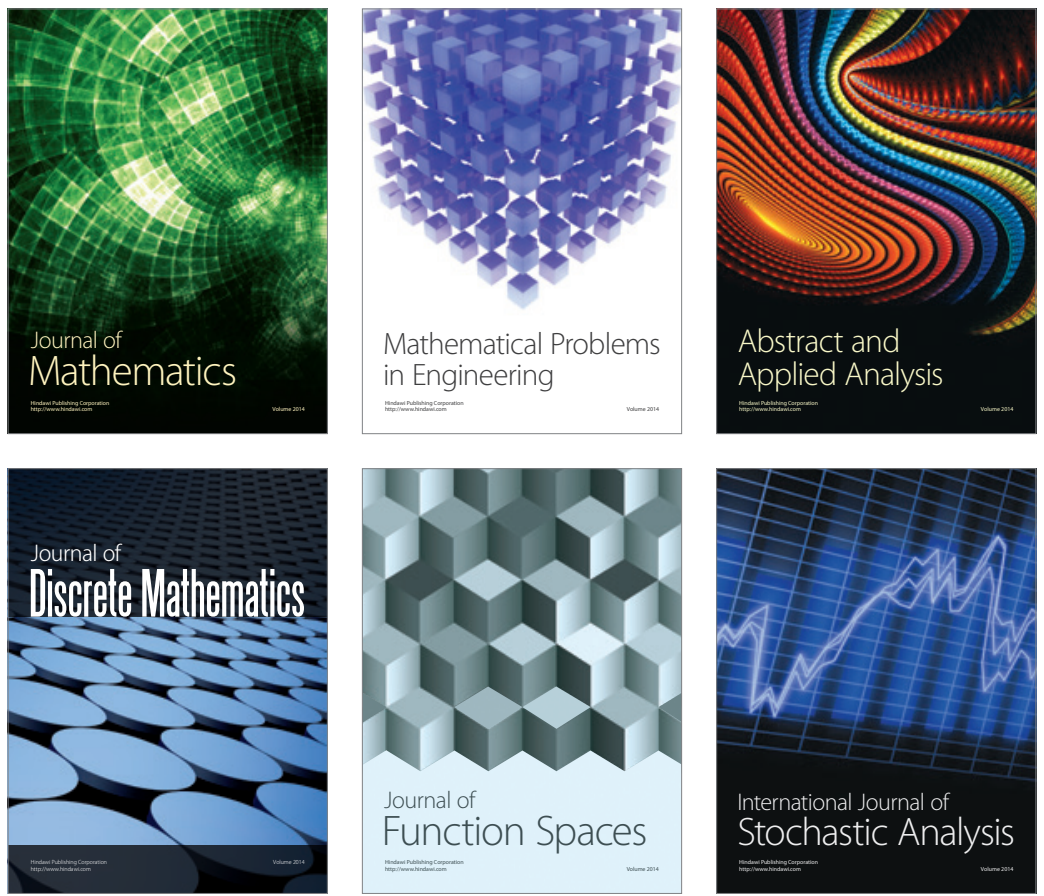

Journal of

Function Spaces

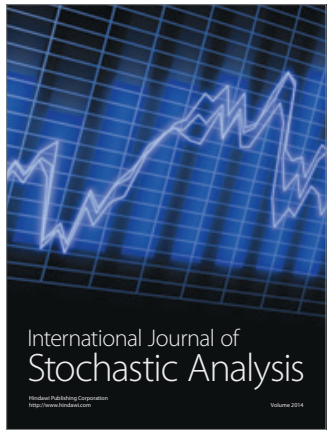

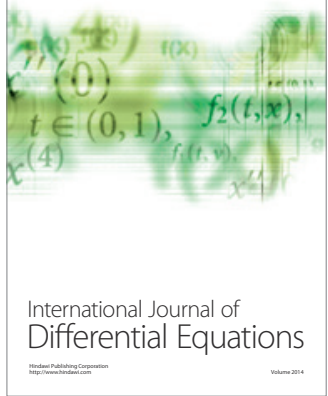
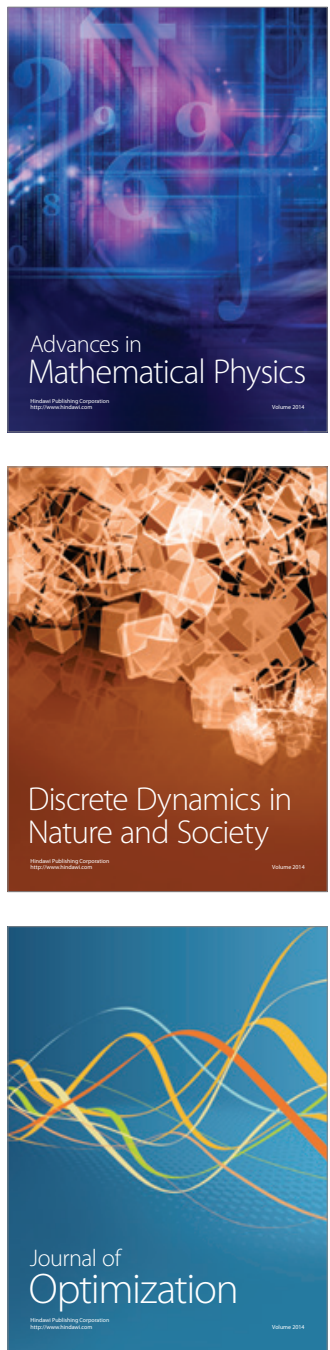